\title{
Constructing a Geodynamic A Priori Seismic (GAPS) velocity model of upper mantle heterogeneity
}

\author{
Mark Rhodes \\ Department of Earth Sciences, University of Liverpool, Liverpool, L69 3BX, UK \\ Now at Statoil, Forusbeen 50, N-4035 Stavanger, Norway

\section{J. Huw Davies} \\ School of Earth, Ocean and Planetary Sciences, CardiffUniversity, Cardiff, CF10 3YE, Wales, UK (buwwearth.cf.ac.uk)
}

[1] Seismic studies of the deep mantle suffer from the fact that the probing seismic waves must traverse the highly heterogeneous and poorly resolved shallow structure. One potential way forward is to develop highresolution models of the crust and upper mantle using other information. Here we describe the construction of a geodynamic a priori model of some aspects of upper mantle seismic velocity heterogeneity. It is based on an equal area tomographic grid and it has been produced at two scales, a $1^{\circ} \times 1^{\circ}$ resolution at the equator, (i.e., each cell has an approximate dimension of $100 \mathrm{~km}$ by $100 \mathrm{~km}$ ), and a $5^{\circ} \times 5^{\circ}$ resolution at the equator. Both have a constant layer thickness of $100 \mathrm{~km}$. Currently, the model accommodates the subducting lithosphere and global variation in continental crustal thickness and age of oceanic lithosphere. The shape of subducting oceanic lithosphere was derived from profiles through seismicity. The shape was combined with estimates of plate velocities and age of subducting lithosphere using an analytic solution of the thermal field to define the slab thermal anomaly. The temperature perturbation was converted to a slowness (1/velocity) perturbation. For oceanic lithosphere, a plate-cooling model was used to convert lithosphere age to slowness perturbation via a temperature perturbation. The variation in the thickness of continental crust, around a global average, formed the third element of the slowness perturbation model. This model has already been applied in a high-resolution mantle tomographic study of lower mantle heterogeneity.

Components: 6718 words, 6 figures, 1 table, 5 data sets.

Keywords: seismology; subduction; slabs; a priori; mantle; model.

Index Terms: 7218 Seismology: Lithosphere and upper mantle; 8124 Tectonophysics: Earth's interior-composition and state (1212); 7207 Seismology: Core and mantle.

Received 20 August 2003; Revised 13 November 2003; Accepted 8 December 2003; Published 31 March 2004.

Rhodes, M., and J. H. Davies (2004), Constructing a Geodynamic A Priori Seismic (GAPS) velocity model of upper mantle heterogeneity, Geochem. Geophys. Geosyst., 5, Q03008, doi:10.1029/2003GC000622.

\section{Introduction}

[2] Seismic studies of the lower mantle are hindered by the fact that the observed signal results from a wave that has to propagate at least once through the crust and upper mantle, twice if the seismic source is shallow. This can be a problem since the level of heterogeneity in the crust and 
upper mantle is very high, while the level of lateral structure in the lower mantle is generally much lower. This shallow heterogeneity can be at a small scale length in the Earth, best resolved by high frequency, short wavelength waves. Unfortunately teleseismic first arrival travel time body wave data sets frequently do not have good vertical resolution in the crust and upper mantle, since such body wave rays travel near vertically through the upper mantle. Therefore in many studies we have that frequently the source of a large part of the signal cannot be accurately constrained, and therefore can be considered noise. Given the small remaining signal, this can lead to a low signal-to-noise ratio, and difficulties in studies of the lower mantle [e.g., Davies et al., 1992; Davies, 1992]. One way to attempt to overcome this is to include data, e.g., surface wave data, which has more sensitivity and resolution in the upper mantle. Another way is to remove surface corrections, as is done with statics corrections in seismic exploration. A further way, an example of which is described here, is to try and circumvent this by using other data to build an a priori model of the heterogeneous structure of the crust and upper mantle.

[3] A potential further advantage of an a priori model for seismic tomography body wave inversion arises from the fact that the inversion problem is strictly nonlinear in that the ray paths required to generate the velocity structure are controlled by the velocity structure being inverted for. This problem is compounded by the fact that the raw data, the arrival times of body wave phases are used to both locate the seismic sources and derive the structure. Such nonlinear processes are best initiated from points close to the correct solution. The a priori model could also possibly help in this respect.

[4] The 3SMAC model of Nataf and Ricard [1996] was constructed as an a priori, seismologically constrained model of upper mantle heterogeneity. It attempts to be a complete a priori model, including such features as hot spots and continental lithosphere, in addition to crust and subducting lithosphere. We adopt a different approach whereby Geodynamic A Priori Seismic (GAPS) velocity model is constructed from a geodynamic stance with intended application in mantle seismic tomo- graphic velocity inversions using teleseismic first arrival P-phase body waves [Rhodes and Davies, 2001]. As such this model should obviously be viewed as only an initial estimate of the levels of the heterogeneity of seismic velocity present in the upper mantle. An attempt is made in this work to account for global variation in continental crust thickness, oceanic lithosphere thickness and effect of subducting slabs. This paper forms the basis for an easily extendible methodology by which models can be constructed which incorporate ever more complex expressions of heterogeneity.

[5] Other seismic a priori models include the crustal models of Cadek and Martinec [1991], CRUST5.1 of Mooney at al. [1998] and CRUST2.0 of Bassin et al. [2000]. These are based on local high resolution seismic studies of the crust, typically using refraction methodology; and correlation using surface geology. While the RUM model of Gudmundsson and Sambridge [1998] is not strictly an a priori model, since it used seismic travel time data to constrain the values of heterogeneous structures; it has similarities in that it did a priori define the shape of the subducting slabs, something which was also undertaken here.

\section{Methodology}

[6] Since this a priori model was ultimately to be used in body wave tomography inversions, the model was built using the layers of equal area cells parameterisation of our tomography inversions. Two versions of the model were produced, one at $1 \times 1$ degree lateral resolution, the other at 5 degree by 5 degree lateral resolution. Both versions had a radial resolution of $100 \mathrm{~km}$. The centre coordinates of each equal area tomographic grid cell were used to elucidate which combination of the three heterogeneous components would be present in each cell and hence in the final a priori model. This was done by testing each cell's coordinates to determine whether it fell within ocean as defined by Müller et al. [1997] and/or any major subduction zone. Subduction zones were defined by closed polygons constructed around each major subduction zone enclosing all of its seismicity. 
Table 1. Data Winnowing Applied to the NEIC ISC Data

\begin{tabular}{ll}
\hline & \multicolumn{1}{c}{ Winnowing Conditions } \\
\hline 1 & No earthquake with a source depth less than $30 \mathrm{~km}$ was included \\
3 & Any earthquake without an entry for the number of observations was disallowed \\
\hline
\end{tabular}

Each heterogeneous component was calculated independently and finally summed together to produce the total perturbation for each cell and hence, the GAPS model. We will now describe the three components in turn starting with subducting oceanic lithosphere.

\section{Subducting Oceanic Lithosphere}

\subsection{Slab Shape}

[7] A global compilation of slab shapes was published in the remarkable compilation of Jarrard [1986] but as the compilation consolidated a variety of published literature, inconsistencies existed between the methods used to produce the published slab shapes. More limiting though for our application was the fact that the shapes are also only presented for representative cross-sections and do not capture the variation along strike. In light of this, we determined the shape of the subducting lithosphere in consistent manner, using profiles through the seismicity via a graphical earthquake browser developed for this project. When this element of the project was undertaken the Engdahl et al. [1998] catalogue was not available, and the National Earthquake (NEIC) CD-ROM of the International Seismological Centre (ISC) earthquake bulletin was employed as the data source for the seismicity. The only data winnowing applied to the earthquake data are listed in Table 1.

[8] It is difficult to decide whether shallow seismicity (less than $30 \mathrm{~km}$ depth) originates along the main thrust zone or within the over-riding plate [Boyd and Spence, 1995] and therefore it was excluded from the development of slab shapes. The interactive graphical browser software enabled the progressive selection of the earthquakes best representing the shape of the Wadati-Benioff zone for profiles through seismicity taken perpendicular to the trench. The coordinates of points defining the trenches [Müller et al., 1997] were re-interpolated to produce a point at least every $40 \mathrm{~km}$ along the length of every convergent margin in the study and each of these points represented the location of a cross-section. An initial algorithmic estimate of the Wadati-Benioff zone location was made by selecting events along a profile. Earthquakes with the largest number of recorded observations were selected as it was assumed that such events would be better located. This algorithmic estimate of upper slab surface location (defined by the selected events) was viewed in the browser and if necessary could be interactively and progressively edited until a satisfactory shape was established. The final result produced the shape of subducting lithosphere at a convergent margin encapsulated by a small population (100s instead of 1000s) of earthquakes. Examples of the slab shape as defined by the small population of earthquakes are shown in Figures 1a and 2a, for the Western Pacific and South America respectively. Earthquakes away from subduction zones are ultimately excluded by the polygons that are drawn to define subduction zones. Figures $1 \mathrm{~b}$ and $2 \mathrm{~b}$ show cross sections through the slab shapes in Kamchatka and Central Andes, defined by the triangles joined by a solid line.

\subsection{Material Path of Subduction and the Thermal Structure}

[9] The azimuth of motion was calculated at each trench point using NUVEL-1 [Gordon, 1995] and a profile was constructed by computing coordinates every $40 \mathrm{~km}$ surface step length along the azimuth of motion, until subduction related seismicity was exhausted. Subsequently a depth was interpolated for all nodes along a profile using the multiquadric exact interpolator method [Hardy, 1971; Saunderson, 1994] operating on the total population of events describing the shape of the Wadati- 


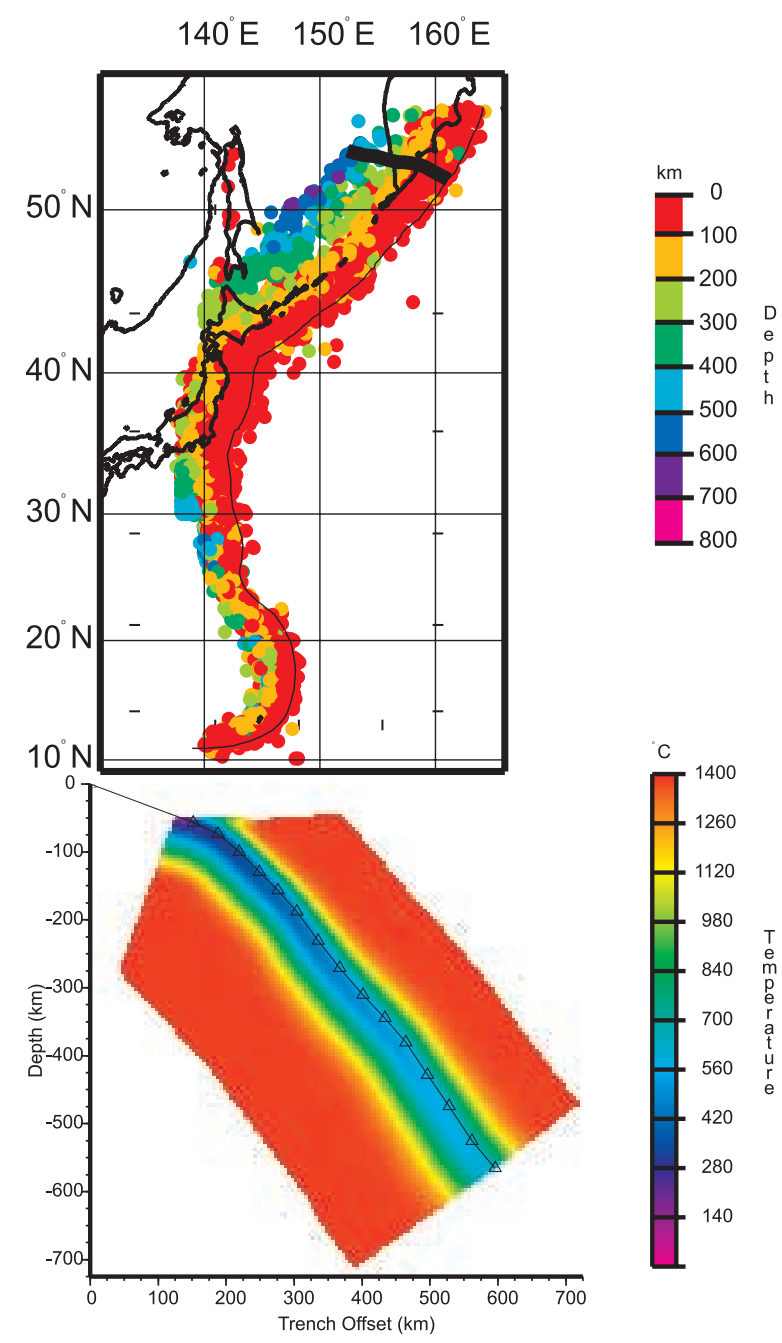

Figure 1. (a) Dot-plot of the population of earthquakes which define the slab shape in the Western Pacific. The color of the dot corresponds to the earthquake depth. Earthquakes away from subduction zones are ultimately ruled out since they do not fall within the polygon for a subduction zone. The actual shape used is obtained from these earthquakes using an interpolator [Hardy, 1971]. (b) Cross-section of the southernmost tip of Kamchatka. The location of the profile is shown by the heavy black line in top right of Figure 1a. The line joining together the triangles represents the interpreted surface of the subducting slab. The horizontal axis is horizontal offset from the trench; while the vertical axis is depth. The figure represents the thermal field as derived using the analytic model of Davies [1999] which incorporates the model of Royden [1993] using the lithosphere age of Müller et al. [1997] and the velocity of convergence of NUVEL-1a [De Mets et al., 1990, 1994]. Note no model is derived shallower than $50 \mathrm{~km}$ depth, since the analytic model probably does not hold at much shallower depth.
Benioff zone along the convergent margin. As material begins to subduct, the azimuth of motion rotates toward the trench (referred to as the material path of subduction) [Creager and Boyd, 1991; Shiono and Sugi, 1985]. Accordingly, each point along a profile was independently rotated toward the trench by an angle determined from the point's location and the local azimuth of the trench. After rotation, each new location along a profile had a new depth calculated.

\subsection{Thermal Regime}

[10] The analytic model of Davies [1999] was used to calculate the thermal regime in and around each
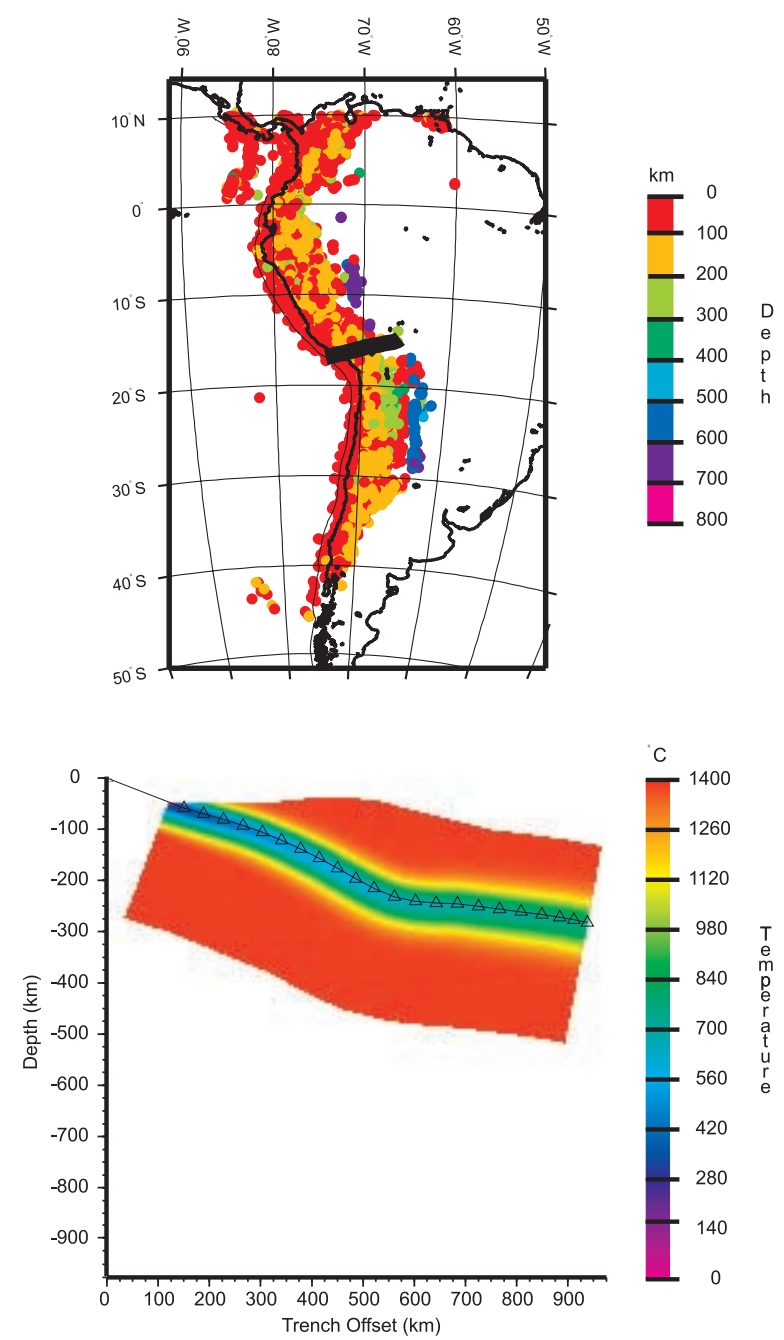

Figure 2. (a) Depth plot of earthquakes in S. America. Similar format to Figure 1a. (b) Thermal field along cross-section through S. Peru, as shown by heavy line in Figure 2a. 
profile of subducting oceanic lithosphere. The solution differs from that of Davies and Stevenson [1992] as it incorporates a cold thermal boundary layer lying adjacent to the slab, moving at the same velocity as the slab, and thereby reducing the conductive warming of the slab. The initial thickness of the slab thermal boundary layer in the mantle wedge was globally fixed, from inspection of the finite element modeling figures of Davies and Stevenson [1992], at $30 \mathrm{~km}$. The analytic solution assumes that flow is parallel to the slab. Again an inspection of the figures produced by Davies and Stevenson [1992] suggested that this assumption holds well for depths greater than $50 \mathrm{~km}$. We are happy to accept these values since both of these assumptions are difficult to test with observations; though we do expect the thickness of the thermal boundary layer to vary weakly with subduction velocity. Also these simple constant assumptions imply that the variations in the resulting thermal structure will be more sensitive to better constrained parameters, e.g., age, convergence velocity etc. Therefore all the temperature calculations were initiated from this $50 \mathrm{~km}$ globally constant depth. Several other parameters are required by the analytic solution; the first is the thickness of the oceanic lithosphere at the trench. This was estimated by substituting the age of the oceanic crust, retrieved from the electronic global compilation of Müller et al. [1997], into the heatflow equations of Stein and Stein [1992]. The lithospheric thickness value was calculated assuming it varied linearly with heatflow. This linear relationship complied with the assumptions and boundary conditions of Royden [1993] whose analytic expression for the two-dimensional (2-D) steady state thermal structure within a wedge and foreland plate was utilised to calculate the second parameter required by the analytic solution, namely the temperature on the top surface of the subducting slab at $50 \mathrm{~km}$ depth. Note that in regions of complex plate history, the age of the subducted plate at depth might have no relationship to the age at the trench. Several other parameters were excluded from the model of Royden [1993], which is a component of Davies [1999], as they were thought to have negligible impact at $50 \mathrm{~km} \mathrm{depth}$; in particular the rate of surface erosion, basal accretion and upper plate heat production. The shear stress was fixed at $20 \mathrm{MPa}$ [Peacock, 1996], the upper and lower layer thermal conductivities were kept fixed, and equal, at $2.5 \mathrm{Wm}^{-1}{ }^{\circ} \mathrm{C}^{-1}$. For each profile the angle of dip of the slab from the trench to $50 \mathrm{~km}$ depth was calculated and included as part of the input parameter set to Royden's analytic solution. The trench depth was retrieved from ETOPO5 [National Geophysical Data Center, 1988]; and the trench location from Müller et al. [1997]. In this way, the parameterization of each temperature profile could uniquely account for shallow ( $<50 \mathrm{~km}$ depth) changes in slab dip and variations in the age of oceanic crust at the trench.

[11] Davies [1999] employs the same coordinate geometry as Davies and Stevenson [1992] whereby the $\mathrm{x}$ axis is perpendicular to the slab surface, positive into the slab, while the positive $y$ axis is in the downdip direction. The shape of the subducting lithosphere was accommodated in the temperature field calculations by using the separation of those nodes lying on the slab surface as the $\mathrm{y}$ axis increment, and taking the $\mathrm{x}$ axis to be perpendicular to the local slab surface. Therefore using these techniques it was possible to construct 2-D temperature profiles that accounted for varying shape for all the major subduction zones. This should be a good approximation provided the change in slab shape is sufficiently small that heat conduction remains primarily perpendicular to the slab surface. This should be easily satisfied since the gradients perpendicular to the slab surface are very high, of order 1000 degrees in less than $100 \mathrm{~km}$. Examples of such thermal profiles are shown in Figure 1b for Kamchatka and Figure 2b for Central Andes. Note that the slab surface is much hotter at $250 \mathrm{~km}$ depth in the Central Andes cross-section than the Kamchatka cross-section. This results from the fact that the lithosphere is initially younger and hence hotter in S. Peru, and also takes much longer to reach $250 \mathrm{~km}$ depth, given the longer distance due to the shallower dip, and therefore each material point has had more time to heat up. Note that the shape of the subducting oceanic lithosphere has been explicitly accounted for in this analytic thermal modeling solution. 


\subsection{A Temperature Perturbation}

[12] When a tomographic grid cell was located within one of the subduction polygons a finer subset of cells was established. The tomographic grid cell was subdivided into 8 blocks (i.e., $2 \times 2 \times$ 2 cells) of dimension approximately $55 \mathrm{~km} \times$ $55 \mathrm{~km} \times 50 \mathrm{~km}$. All the temperatures, for the subduction zone under investigation, were processed and any falling within the blocks were stored and eventually averaged. If there were no temperature nodes falling within a block, the cell's temperature was set to be the ambient mantle temperature, $1370^{\circ} \mathrm{C}$. (Since GAPS is constructed from the lateral thermal perturbations, the exact value chosen for the ambient mantle temperature has no influence on the final model). Layer averages for each of the two layers were then calculated and combined to give a total average temperature for the tomographic cell. As the temperature calculations were fixed to start at $50 \mathrm{~km}$ depth, the thermal averages in the 0 to $50 \mathrm{~km}$ range were set to be equal to those in the cells directly beneath, i.e., in the 50 to $100 \mathrm{~km}$ region. Once the averages had been calculated, a thermal perturbation was calculated by subtracting from the average temperature the ambient mantle temperature.

\subsection{A Slowness (Velocity) Perturbation}

[13] The conversion coefficients from temperature perturbation to velocity perturbation (or slowness perturbation) are subject to large (up to $100 \%$ ) variations [de Jonge et al., 1994]; this makes a convincing selection difficult to make. Therefore a simple constant relationship between thermal perturbation and slowness perturbation was applied for all thermal regimes. The mapping was achieved via a relationship of the form given in equation (1).

$$
d s=\beta d T
$$

where $d s$ is slowness perturbation, $d T$ is the temperature perturbation and $\beta$ is the constant which is given by

$$
\beta=\frac{\alpha}{v_{\text {ref }}^{2}}
$$

where $\alpha$ is $d V_{p} / d T$ and $v_{\text {ref }}$ is the velocity in the reference model. We used a constant value of $\beta$ equal to $-6.3 * 10^{-6} \mathrm{~s} \mathrm{~km}^{-1} \mathrm{~K}^{-1}$. If $\mathrm{v}_{\text {ref }}$ is equal to
$8.9 \mathrm{~km} \mathrm{~s}^{-1}$ this implies that $\alpha$ was $-5 * 10^{-4} \mathrm{~km}$ $\mathrm{s}^{-1} \mathrm{~K}$ (agreeing well with other values quoted in the literature; for example [Boyd and Spence, 1995; Spakman et al., 1989; Goes et al., 2000]).

\section{Oceanic Lithosphere}

[14] All the tomographic cells falling in the oceans had a slowness contribution derived from a thermal profile calculated at the cell's central location using the plate cooling model of oceanic lithosphere [McKenzie, 1967] combined with the straightforward conversion of distance to age using plate velocity, as done by Parson and Sclater [1977] for example. The equation stems from a solution of the heat equation with the system assumed to be in steady state with negligible internal heating. All the thermal models were calculated assuming plate thickness of $100 \mathrm{~km}$, a thermal diffusivity of $10^{-6} \mathrm{~m}^{2} \mathrm{~s}^{-1}$, a mantle temperature of $1370^{\circ} \mathrm{C}$ and a surface temperature of $0^{\circ} \mathrm{C}$. The age of the oceanic lithosphere for the cell centres located in the oceans was extracted from the Müller et al. [1997] data set. A temperature profile was constructed by calculating a temperature every $5 \mathrm{~km}$ depth over the $100 \mathrm{~km}$ thick plate; the temperatures within each profile were then summed and averaged.

\subsection{A Temperature Perturbation}

[15] A temperature perturbation was produced by subtracting the average temperature for the oldest oceanic lithosphere stored in the Müller et al. [1997] data set from the average temperature at a cell location. These temperature perturbations define the magnitude of the slowness contribution due to the cooling oceanic lithosphere. However, the Müller et al [1997] data set is incomplete; various oceanic regions have no associated age. In this initial model, no attempt was made to recover an age estimate for such regions. The results of the thermal modeling on a $5^{\circ} \times 5^{\circ}$ equal area tomographic grid are shown in Figure 3a, as expected it mimics the age of oceanic crust.

\subsection{A Slowness (Velocity) Perturbation}

[16] The temperature perturbations were converted to slowness perturbations employing equation (1). 


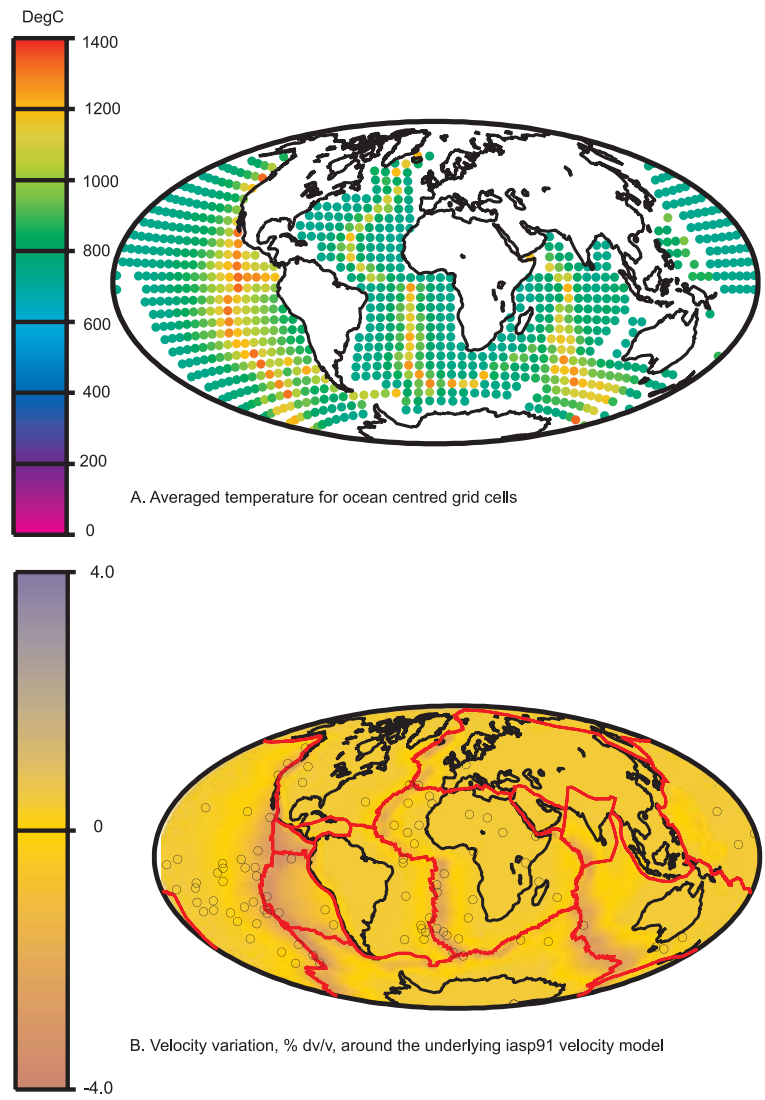

Figure 3. (a) Dot-plot of the average temperature for grid cells whose centre falls within ocean, as defined by Müller et al. [1997]. Note some oceanic cells are white since they do not have an age in the Mueller data. For our application of the model to global body wave tomography these missing data were not a problem. Uses of the model for other applications might require one to assign values to all the cells for consistency. (b) A map showing the seismic heterogeneity at $50 \mathrm{~km}$ depth, relative to iasp91 [Kennett and Engdahl, 1991]. This is an average of the structure over the top $100 \mathrm{~km}$.

This time, a value of $\beta$ equal to $-8.4 \times 10^{-6}$ was used. Assuming $\mathrm{v}_{\text {ref }}$ is equal to $8.0 \mathrm{kms}^{-1}$ for the oceans, then this is equal to choosing $\alpha$ equal to $-5.4^{*} 10^{-4} \mathrm{kms}^{-1}{ }^{\circ} \mathrm{C}$ which is the low pressure, high temperature elastic constant defined in Anderson and Isaak [1992] for olivine. Figure 3b shows a map of the velocity perturbation resulting from the oceanic lithosphere.

\section{Continental Crustal Thickness}

[17] The variation of crustal thickness around a globally defined average Moho depth value de- termined the magnitude of the velocity perturbation in GAPS. This was only undertaken on continents. The crustal thickness variations over the oceans are less, and not as well defined. If the crust extended deeper than the average Moho depth then slower, lower crustal velocities was assumed to be present deeper into the tomographic cell. On the other hand, if the base of the local crust was shallower than the global average Moho depth, faster velocity mantle material was assumed to be present closer to the surface of the Earth. Initially, the degree and order 30 spherical harmonic model of Cadek and Martinec [1991] was used but this resulted in a pronounced Gibbs phenomenon west of the Peru Andes-Pacific margin. This was rectified by using their degree and order 70 model (Z. Martinec, personal communication, 1996). Figure 4a shows the crustal thickness for continent centres grid cells. We note that this work was started before Crust5.1 [Mooney at al., 1998], and CRUST2.0 [Bassin et al., 2000] were available which would have been other alternatives.

[18] Since our ultimate objective was to use this model in seismic tomography, it was important to reconcile the reference velocity model used in tomography to (re-)locate the events [van der Hilst and Spakman, 1989] and that used to construct the a priori model. Therefore for congruency, the Moho depth defined in the iasp91, one-dimensional (1-D) radially symmetric velocity model [Kennett and Engdahl, 1991] was used to calculate velocity perturbations due variation in crustal thickness. This reference velocity model corresponds to that used in the re-processed Engdahl et al. [1998] phase catalogue which was subsequently used in simultaneous inversions for mantle seismic velocity heterogeneity and earthquake relocation [Rhodes, 1998]. The iasp91 velocity model defines a two layer crust with upper layer velocity of $5.8 \mathrm{kms}^{-1}$, lower layer velocity of $6.5 \mathrm{kms}^{-1}$ and Moho depth of $35 \mathrm{~km}$.

\subsection{A Slowness (Velocity) Perturbation}

[19] A linear velocity function defines the iasp91 velocity model from 35 to $100 \mathrm{~km}$. Therefore when the crustal thickness, $d_{c}$, is greater than 


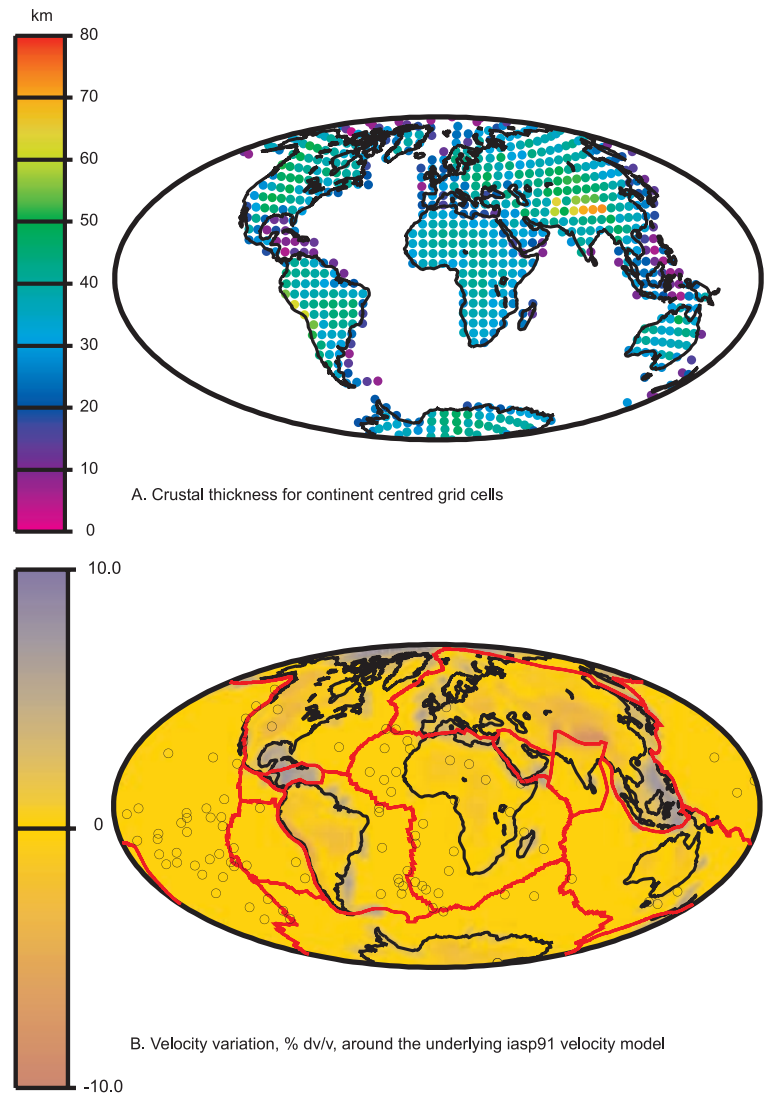

Figure 4. (a) Dot-plot of the crustal thickness [Cadek and Martinec, 1991] for grid cells whose centre falls within continent. (b) A map showing the velocity perturbations around iasp91 at $50 \mathrm{~km}$ depth. It is interesting to note that some of the largest anomalies result from the thin crust on continental shelves, and regions that arguably Müller et al. [1997] could have defined as ocean, e.g., Caribbean. This is an average of the structure over the top $100 \mathrm{~km}$.

$35 \mathrm{~km}$, the velocity perturbation is defined by equation (3)

$$
d v=\frac{\left(d_{c}-\text { Moho }_{\text {iasp } 91}\right)\left(V_{\text {lower }}-V_{m}\right)}{\text { GridDepth }}
$$

where $M o h o_{\text {iasp } 91}$ is defined as $35 \mathrm{~km} ; V_{\text {lower }}$ as $6.5 \mathrm{kms}^{-1}$; GridDepth as the layer thickness which for GAPS was set to $100 \mathrm{~km}$ and $V_{m}$, the average mantle velocity over the anomalous depth interval under consideration, is defined in equation (4)

$$
V_{m}=\left(\frac{V_{\text {GridDepth }}-V_{m 35}}{\text { GridDepth }- \text { Moho }_{\text {iasp } 91}}\right)\left(\frac{d_{c}-\text { Moho }_{\text {iasp } 91}}{2}\right)+V_{m 35}
$$

where $V_{\text {GridDepth }}$ is the velocity at the base of the cell. This assumes that the mantle velocity is linear in depth in the uppermost mantle. Similar logic applies when the crustal thickness is less than $35 \mathrm{~km}$.

[20] Slowness is defined as the reciprocal of velocity and therefore slowness perturbation is given by equation (5)

$$
d s=-\frac{d v}{v_{r e f}^{2}}
$$

where $\mathrm{v}_{\text {ref }}$ is the average velocity from the actual Moho depth to $100 \mathrm{~km}$ depth.

[21] In this way the slowness perturbations of continental crustal thickness around iasp91 can be calculated for all cells falling within continental regions. The resulting velocity variation is shown in Figure $4 \mathrm{~b}$. We note that the largest positive anomalies are found in the thin marine crust bounding continents, including large continental shelves. Some of these might be incorrectly identified by Mueller as continental regions, e.g., Caribbean, but they are small in extent.

\subsection{GAPS: An A Priori Model of Upper Mantle Seismic Heterogeneity}

[22] To produce the final model, GAPS, the results from the modeling of individual components were summed and then the layer averages removed. The layer average is removed since GAPS does not try to develop an a priori 1-D velocity model, but rather tries only to develop an a priori estimate of lateral structure. Each layer average is not automatically zero since we have chosen arbitrary reference temperatures; e.g., ambient mantle in the subducting slab calculations, and the oldest lithosphere in the oceanic plate calculations. It also means that the exact choice of the reference for each component for GAPS is irrelevant.

[23] In Figure 5 we show GAPS at 4 different depths. We note that the bulk of the heterogeneity in this model is in the shallowest layer (centered at $50 \mathrm{~km}$ depth). As mentioned before, GAPS limits the heterogeneity that it considers, and therefore it makes no attempt to capture all the seismic heterogeneity that might be present. Below the first layer, the only contributor to the model is subducted lithosphere. Another striking feature is how little of the upper mantle is occupied by subducting 

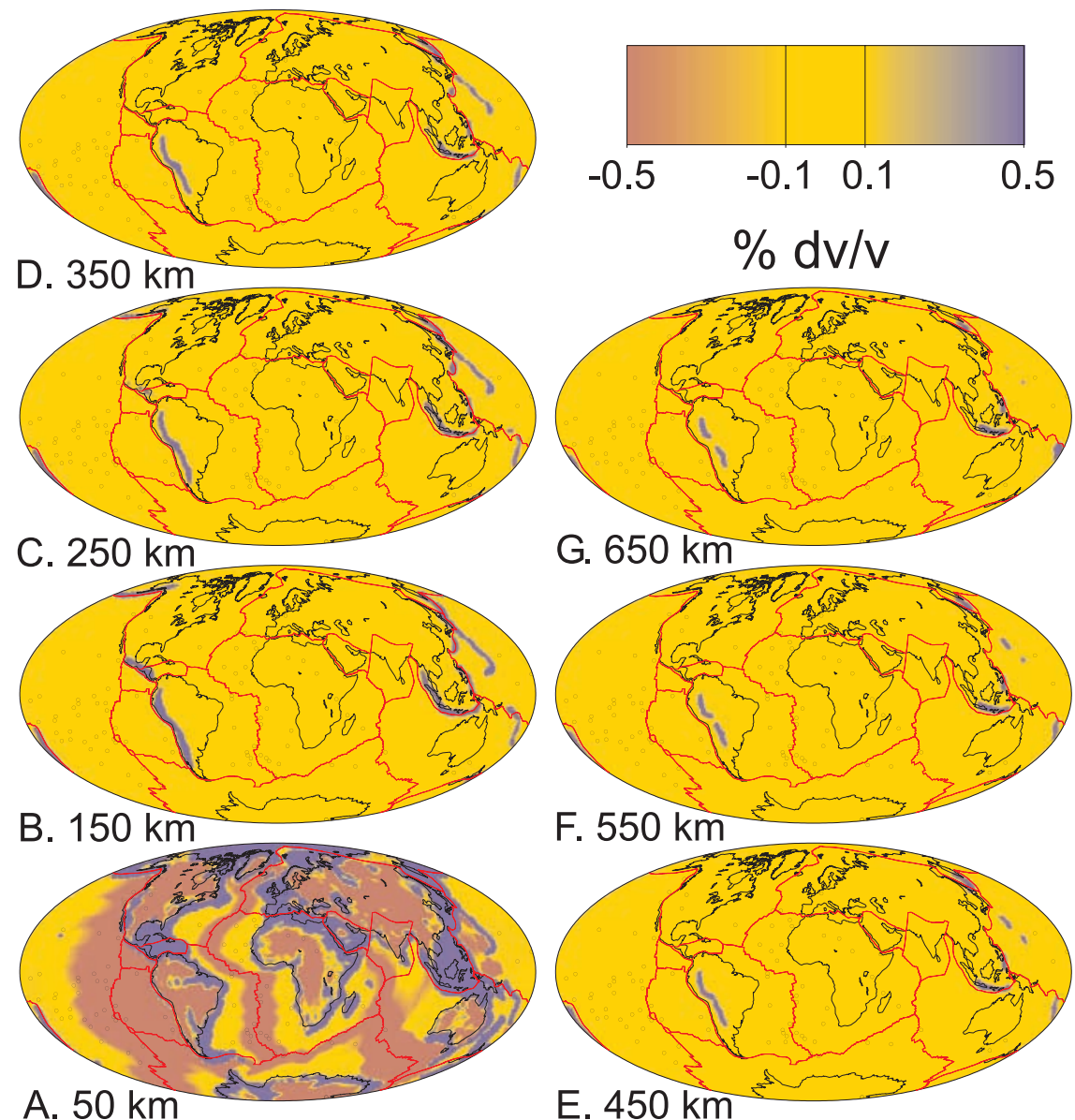

A. $50 \mathrm{~km}$

E. $450 \mathrm{~km}$

Figure 5. This figure shows the total GAPS model. The model is shown in each $100 \mathrm{~km}$ thick layer, starting at $50 \mathrm{~km}$ depth down to $650 \mathrm{~km}$ depth. We note that the $50 \mathrm{~km}$ depth, includes contribution from crustal thickness, oceanic lithosphere age and subduction; while the other depths, down to $650 \mathrm{~km}$ depth, include only signal from subducting slabs. The depths are therefore at the middle of the layers that are averaged.

lithosphere. A significant aspect of this model is that it is a model of lateral velocity heterogeneity, and not a model of the absolute seismic velocity. While the continental crustal thickness component was developed assuming iasp91, in principle there is no reason why this a priori model could not be used with any reference radial model.

[24] GAPS is available in three forms, as data set 1, a 770KB ASCII text file, data set 2, a $17.2 \mathrm{MB}$ ASCII text file, and data set 3, a 14.1 MB ASCII file (see auxiliary material ${ }^{1}$ ). Data set 1 is the GAPS model on the cruder 5 degree by 5 degree equal area grid, in $100 \mathrm{~km}$ depth increments,

${ }^{1}$ Auxiliary material is available at $\mathrm{ftp} / / \mathrm{ftp}$.agu.org/apend/gc/ 2003GC000622. starting at $650 \mathrm{~km}$ depth. The file has one header line followed by 11578 lines of the model (7 layers with 1654 cells in each layer). Each line consists of 7 floating point numbers. These are the latitude, longitude, and depth of the cell centre (in degrees, degrees and $\mathrm{km}$ respectively), followed by the subduction, continental crust, oceanic lithosphere, and total slowness perturbation (all in $\mathrm{s} / \mathrm{km}$ ). Data set 2 is the GAPS model on the finer 1 degree by 1 degree equal area grid. It is the same as the above except it now has 288765 lines, one header line followed by 7 layers with 41252 cells in each layer. Both these versions of the model have not had the layer average removed and therefore it is clearer which cells actually contribute to the model (i.e., the nonzero cells). Data set 3 is on the 1 degree by 1 degree grid, but consists of 5 floating point 
numbers for each cell. These are the longitude (degrees), latitude (degrees) depth $(\mathrm{km})$ of cell centre, the total slowness perturbation $(\mathrm{s} / \mathrm{km})$, and the total slowness perturbation with layer average removed $(\mathrm{s} / \mathrm{km})$. A second model is made available; GAPS(S) which only has the subducted slab component of the model. Data set $4(418 \mathrm{kB})$ is GAPS(S) at $5 \times 5$ degree (equivalent to data set 1 ), and data set $5(10.4 \mathrm{MB})$ is it at $1 \times 1$ degree (equivalent to data set 2). This will make GAPS easier to use for workers who want to incorporate more recent a priori crustal structure models, such as CRUST5.1 and CRUST 2.0.

\section{Discussion}

[25] GAPS contrasts to 3SMAC [Nataf and Ricard, 1996], which is a comprehensive a priori model of the absolute seismic velocity for the upper mantle using all the information available. We note that 3SMAC includes much more information than GAPS, including estimates of the thickness of ice and sediment layers, as well as estimates of the influence of mantle plumes and lithospheric roots. In $3 \mathrm{SMAC}$, the $2^{\circ} \times 2^{\circ}$ cells which contained deep seismicity were assumed to contain a subducting slab. Therefore the slab signature is derived more crudely in 3SMAC than in GAPS. GAPS is not only higher resolution but also takes account of the age and velocity of the subducting lithosphere. The resolution of 3SMAC though is more than adequate for the free-oscillation and surface wave investigations to which it has been applied. For relatively low resolution global studies the difference in the slab structure between the two models is expected to be minimal. The difference starts to appear at $\sim 100 \mathrm{~km}$ resolution. The more detailed subducting slab signature of GAPS will be especially useful in body wave studies. It should be useful in the relocation of events in subducting plates where the higher resolution of structure could be useful. The philosophy of GAPS is to only incorporate information that is known with a fair degree of accuracy independent of global seismic studies. Therefore the dominant signal of 3SMAC, the roots of continental lithosphere, was not included in GAPS, since we felt they were not as well constrained as the other components. All the signal beneath $100 \mathrm{~km}$ depth in GAPS arises from subducting slabs.

[26] Points of discussion in developing this model, are the restricting of the crustal thickness solely to continental regions, and restricting estimates of lithosphere anomalies solely to oceanic lithosphere. This was done, since these were felt to be the major contributor to variation in these regions that were well constrained. Crustal thickness variation in oceanic crust is by and large small away from oceanic plateaus, and is not as well characterized as thickness on continents. Since the seismic impact of variations in thickness of continental lithosphere is largely derived by the same data that we would ultimately use in our lower mantle studies; we decided not to include it in this a priori model. CRUST 5.1, and 2.0 are higher resolution crustal models, that include velocities of up to 7 different layers; therefore this is substantially more detail than the simple crustal model (thickness alone) used here.

[27] While we have motivated the model as an a priori model for studies of the lower mantle; the model could have other uses. For example it can provide a detailed model of the thermal structure of subduction zones along strike. In Figure 6 we show the temperature at the slab surface at $100 \mathrm{~km}$ depth along strike of the Aleutian arc. These variations are of interest to petrologists trying to understand subduction zone magmatism, and the nature of the fluid and sediment input from the subducting slab. We note that the temperatures beneath the Alaskan peninsula are higher than beneath the central Aleutian arc, this is due to the shallower dip beneath the Alaskan peninsula, and the longer time that the lithosphere takes to reach $100 \mathrm{~km}$ depth. Also the model would have hotter temperatures in the westernmost part of the arc, since here the velocity is largely strike-slip and the actual convergence velocity is very low; but since it is so hot, there is no seismicity, hence no slab was defined in this region of the model. Another use for the model could be for geodynamicists who could use the slab shapes to possibly constrain the controls on the global variation of slab deformation. 


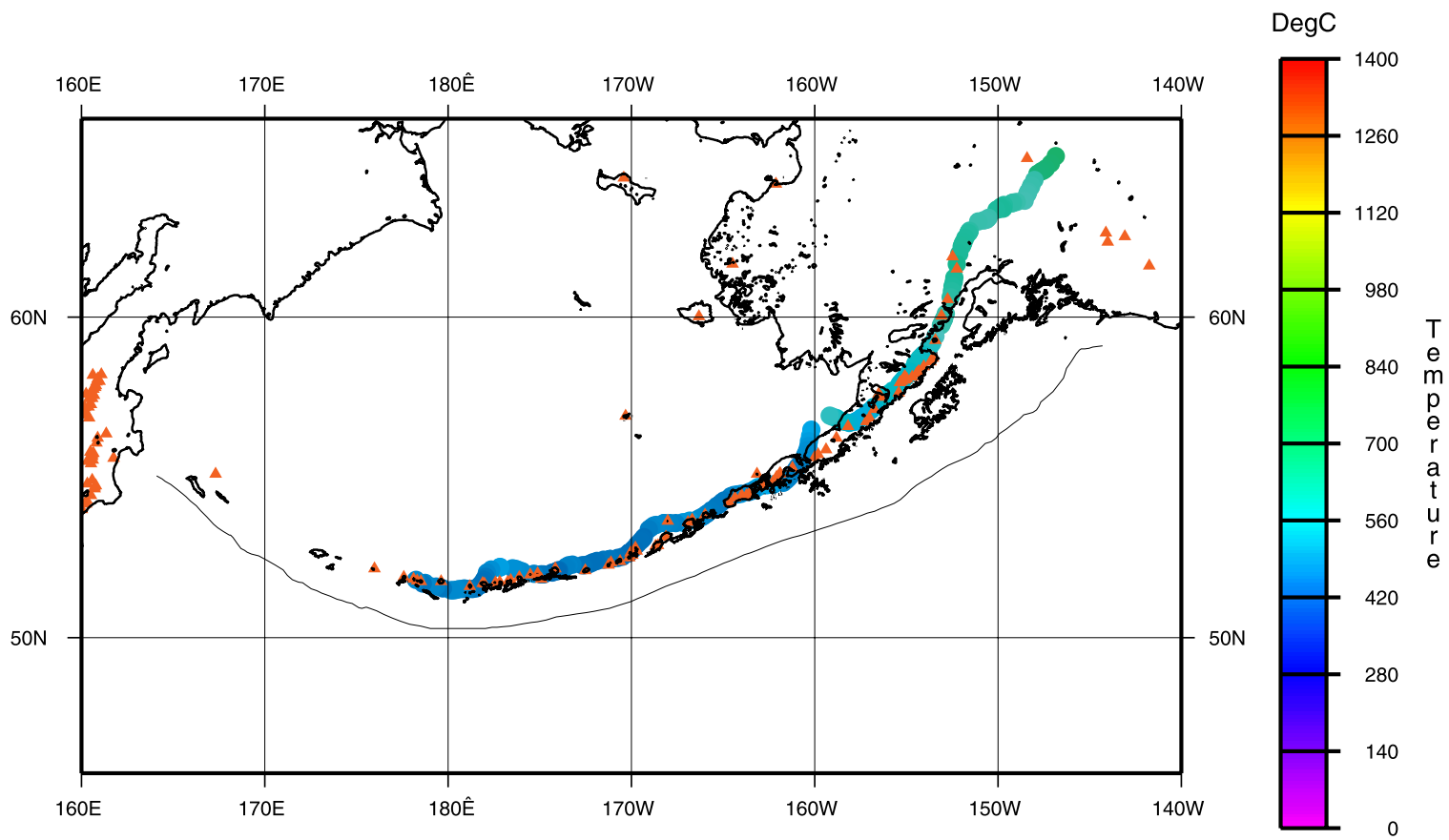

Figure 6. This figure shows the temperature along-strike in the Aleutians subduction zone at $100 \mathrm{~km}$ depth at the slab surface. The figure also shows the location of quaternary volcanoes in this region, which are typically some $125 \mathrm{~km}$ above the estimated subducted slab, a similar value to that quoted in other studies.

[28] This model has been applied to global mantle studies in an attempt to reduce the impact of shallow structure in studies of the deep Earth using teleseismic P phases from the Engdahl et al. [1998] phase catalogue [Rhodes, 1998; Rhodes and Davies, 2001]. The a priori model rather than station corrections (statics) was used to attempt to account for the poorly resolved shallow structure. The resulting models fit the data very well. They contain plume-like features beneath "hot spots" extending down, in some cases, into the midmantle. This depth might be the limit of imaging such small slow anomaly features from travel time tomography due to wave front healing effects. On the basis of teleseismic data alone there is no way to differentiate between this class of model and models derived using "statics" which do not image such plume-like features. The GAPS model presented here thus provided the means to sensibly illustrate such nonuniqueness for such data sets, and show that plume-like structures are not inconsistent with teleseismic body wave data sets. Further improvements that might be considered to this a priori model include incorporating CRUST 5.1, 2.0 [Mooney et al., 1998; Bassin et al., 2000], and models of hot spots and continental lithosphere (e.g., 3SMAC).

\section{Acknowledgments}

[29] MR acknowledges the receipt of a University studentship from the University of Liverpool. HD acknowledges the use of NESSC funded by HEFCE-JREI JR99LIDAEQ, and Helix funded by HEFCW-SRIF. All the global displays were produced using the Generic Mapping Tool (GMT) product of Wessel and Smith [1995].

\section{References}

Anderson, O. L., and D. Isaak (1992), High-temperature elastic constant data on minerals relevant to geophysics, Rev. Geophys., 30, 57-90.

Bassin, C., G. Laske, and G. Masters (2000), The Current Limits of Resolution for Surface Wave Tomography in North America, EOS Trans AGU, 81, F897.

Boyd, T. M., and W. Spence (1995), Seismic cycles along the Aleutian arc: Analysis of seismicity from 1957 through 1991, J. Geophys. Res., 100, 621-644.

Cadek, O., and Z. Martinec (1991), Spherical harmonic expansion of the Earth's crustal thickness up to degree and order 30, Stud. Geophys. Geoid, 35, 151-165.

Creager, K. C., and T. M. Boyd (1991), The geometry of Aleutian subduction: Three dimensional kinematic modelling, J. Geophys. Res., 96, 2293-2307. 
Davies, J. H. (1992), Lower bound estimate of average earthquake mislocation from variance of travel-time residuals, Phys. Earth Planet. Inter., 75, 80-101.

Davies, J. H. (1999), Simple analytic model for subduction zone thermal structure, Geophys. J. Int., 139, 823-828.

Davies, J. H., and D. J. Stevenson (1992), Physical model of the source region of subduction zone volcanics, J. Geophys. Res., 92, 2037-2070.

Davies, J. H., O. Gudmundsson, and R. W. Clayton (1992), Spectra of mantle shear wave velocity structure, Geophys. J. Int., 108, 865-882.

de Jonge, M. R., M. J. R. Wortel, and W. Spakman (1994), Regional scale tectonic evolution and the seismic velocity structure of the lithosphere and upper mantle: The Mediterranean region, J. Geophys. Res., 99, 12,091-12,108.

De Mets, C., R. G. Gordon, D. F. Argus, and S. Stein (1990), Current plate motions, Geophys. J. Int., 101, 425-478.

De Mets, C., R. G. Gordon, D. F. Argus, and S. Stein (1994), Effect of recent revisions to the geomagnetic reversal timescale on estimates of current plate motions, Geophys. Res. Lett., 21, 2191-2194.

Engdahl, E. R., R. D. van der Hilst, and R. Buland (1998), Global teleseismic earthquake relocation with improved travel times and procedures for depth determination, Bull. Seismol. Soc. Am., 88, 722-743.

Goes, S., R. Govers, and P. Vacher (2000), Shallow mantle temperatures under Europe from $\mathrm{P}$ and S-wave tomography, J. Geophys. Res., 105, 1153-1169.

Gordon, R. (1995), Present plate motions and plate boundaries, in Global Earth Physics: A Handbook of Physical Constants, AGU Ref. Shelf Ser., vol. 1, edited by T. Ahrens, pp. 6687, AGU, Washington, D.C.

Gudmundsson, O., and M. Sambridge (1998), A regionalized upper mantle (RUM) seismic model, J. Geophys. Res., 103, $7121-7136$.

Hardy, R. L. (1971), Multiquadric equations of topography and their irregular surfaces, J. Geophys. Res., 76, 1905-1915.

Jarrard, R. D. (1986), Relations among subduction parameters, Rev. Geophys., 24, 217-284.

Kennett, B. L. N., and E. R. Engdahl (1991), Traveltimes for global earthquake location and phase identification, Geophys. J. Int., 105, 429-465.

McKenzie, D. (1967), Some remarks on heat flow and gravity anomalies, J. Geophys. Res., 72, 6261-6273.
Mooney, W. D., G. Laske, and T. G. Masters (1998), CRUST 5: 1 . A global crustal model at 5 degree $\times 5$ degree, J. Geophys. Res., 103, 727-747.

Müller, R. D., W. R. Roest, J. Y. Royer, L. M. Gahagan, and J. G. Sclater (1997), A digital map of the ocean floor, J. Geophys. Res., 102, 3211-3214.

Nataf, H. C., and Y. Ricard (1996), 3SMAC: An a priori tomographic model of the upper mantle based on geophysical modelling, Phys. Earth Planet. Inter., 95, 101-122.

National Geophysical Data Centre (NGDC) (1988), ETOPO5 bathymetry/topography data, National Oceanic and Atmospheric Administration, U.S. Dept. Comm., Boulder, Colo.

Parson, B., and J. G. Sclater (1977), An analysis of the variation of ocean floor bathymetry and heat flow with age, J. Geophys. Res., 82, 803-827.

Peacock, S. M. (1996), Thermal and petrologic structure of subduction zones, in Subduction: Top to Bottom, Geophys. Monogr. Ser., vol. 96, edited by G. E. Bebout et al., pp. 119133, AGU, Washington, D. C.

Rhodes, M. (1998), Mantle seismic tomography using P-wave travel times and a priori velocity models, Ph.D thesis, Univ. of Liverpool, Liverpool.

Rhodes, M., and J. H. Davies (2001), Tomographic imaging of multiple mantle plumes in the uppermost lower mantle, Geophys. J. Int., 147, 88-92.

Royden, L. H. (1993), The steady state thermal structure of eroding orogenic belts and accretionary prisms, J. Geophys. Res., 98, 4487-4507.

Saunderson, H. C. (1994), Multiquadric surfaces in C, Computers and Geosciences, 20, 1103-1122.

Shiono, K., and N. Sugi (1985), Life of an oceanic plate: Cooling time and assimilation time, Tectonophysics, 112, $35-50$.

Spakman, W., S. Stein, R. van der Hilst, and R. Wortel (1989), Resolution experiments for NW Pacific subduction zone tomography, Geophys. Res. Lett., 16, 1097-1100.

Stein, C. A., and S. Stein (1992), A model for the global variation in oceanic depth and heat flow with lithospheric age, Nature, 359, 123-129.

van der Hilst, R. D., and W. Spakman (1989), Importance of the reference model in linearized tomography and images of subduction below the Carribean plate, Geophys. Res. Lett., 16, 1093-1096.

Wessel, P., and W. H. F. Smith (1995), New version of the Generic Mapping Tools released, Eos Trans. AGU, 76, 329. 